\title{
Association of asthma and total IgE levels with human leucocyte antigen-DR in patients with grass allergy
}

\author{
G. Woszczek, M.L. Kowalski, M. Borowiec
}

\begin{abstract}
Association of asthma and total IgE levels with human leucocyte antigen-DR in patients with grass allergy. G. Woszczek, M.L. Kowalski, M. Borowiec. (C)ERS Journals Ltd 2002.

ABSTRACT: Exposure to grass pollens during the pollen season, reveals in sensitive patients symptoms of allergic rhinitis, conjunctivitis and/or bronchial asthma. It is not well understood why, in some patients, only symptoms of rhinitis occur while in others similar exposure causes symptoms of asthma and rhinitis.

An association study is reported here, where the possible contribution of human leucocyte antigen (HLA)-DR gene polymorphisms to differential phenotypic expression of symptoms in patients with grass-pollen allergy was determined. HLA-DR genotyping was performed by the polymerase chain reaction with the sequence-specific primers method in 82 patients with symptoms of seasonal allergic rhinitis and/or bronchial asthma and 52 healthy nonatopic control subjects.

A significant association was found between HLA-DRB1*02, B5* haplotype and asthma phenotype in patients with grass-pollen allergy when compared to patients with rhinitis only. Significantly higher total serum immunoglobulin $E$ levels were observed in patients with HLA-DRB1*01 alleles in comparison to patients without these alleles.

The data in this study suggest that human leucocyte antigen-DR locus, or other genes in linkage disequilibrium, may play an important role in asthma phenotype expression in patients with grass-pollen allergy as well as in determining total immunoglobulin $\mathbf{E}$ levels in these patients.

Eur Respir J 2002; 20: 79-85.
\end{abstract}

Dept of Clinical Immunology and Allergy, University Medical School of Lodz, Lodz, Poland.

Correspondence: M.L. Kowalski, Dept of Clinical Immunology and Allergy, Medical University of Lodz, 251, Pomorska str., 92-213 Lodz, Poland. Fax: 48426782292

E-mail: marek.kowalski@csk.am. lodz.pl

\section{Keywords: Allergy}

asthma

genetics

grass pollens

human leucocyte antigen alleles total immunoglobulin E

\section{Received: July 102001}

Accepted after revision: January 28 2002

This study was supported by a grant from the State Committee for Scientific Research No. 4P05B07909.
Grass-pollen allergy affects nearly $20 \%$ of the European population [1]. Exposure to grass pollens reveals, in sensitive patients, symptoms of rhinitis, conjunctivitis and/or bronchial asthma. It is not well understood why, in some patients, only symptoms of rhinitis occur while in others, similar exposure causes symptoms of asthma and rhinitis. In patients sensitive to grass pollens, allergen exposure may lead to symptoms of rhinitis followed, in a few years time, by asthmatic symptoms ("an allergy march"). However, clinical observations have shown that some patients with rhinitis never develop symptoms of asthma [2]. In the study of SeTtipane et al. [3] only $10.5 \%$ of patients with rhinitis developed asthma during 23 yrs of observation. Similarly, DANIELSON and JENSEN [2] reported that asthma appeared in only $6 \%$ of patients with allergic rhinitis during 7 yrs of follow-up. Thus in the majority of patients with rhinitis, the atopic disease phenotype remains stable for a long period of time, possibly for life.

Differential manifestation of allergic diseases may result from both genetic and environmental factors. For example MAO et al. [4] demonstrated that atopic eczema, but not asthma or rhinitis, was significantly associated with polymorphism of the mast-cell chymase gene. The inheritance pattern of asthma demonstrates that it is a complex genetic disorder. Genome-wide studies showed strong linkage of asthmatic phenotypes to several loci [5, 6]. Postma et al. [7] linked bronchial hyperreactivity (BHR) to chromosome $5 \mathrm{q}$ and concluded that a gene regulating $\operatorname{IgE}$ levels may be responsible for bronchial hyperreactivity. These data point to the possible influence of high serum IgE levels in the development of asthma. It has been shown that high serum IgE levels and skin-test reactivity are associated with asthma development [8]. Markers on chromosome 5q and 11q13 were reported to be associated with total IgE concentrations [9, 10]. Epidemiological studies [11, 12] have demonstrated that total serum IgE levels are mainly determined by genetic factors, and other factors such as age, sex, allergen exposure or tobacco smoke have a relatively small influence on its level [13].

Among genetic factors contributing to the development of atopic diseases, human leucocyte antigen (HLA) genes have been implicated in triggering an allergen-specific IgE response. HLA-DR alleles were found to be associated with the development of specific IgE reactions to seasonal [14] and perennial allergens [15] and to some drugs [16]. A different role for HLA gene polymorphisms has been suggested by a study of Blumenthal et al. [17], who found that in 
pollen allergy the asthma phenotype may be associated with major histocompatibility complex (MHC) extended haplotype (HLA-B7/SC31/DR2) and patients with rhinitis alone have increased frequency of (HLA-B8/SC01/DR3) haplotype. Similarly, MoffATt et al. [18] showed association of extended tumour necrosis factor (TNF)- $\alpha /$ HLA-DR haplotypes with asthma and BHR. But it is still not clear whether HLA genes themselves or other linked genes are partly responsible for differentially manifested disease.

HLA-DR loci may play an important role in the pathophysiology of allergic inflammation by influencing specific IgE responses. In this study, the associations of HLA-DR alleles with organ-specific expression of atopic disease, namely rhinitis or rhinitis and bronchial asthma and with total serum IgE levels in patients with seasonal grass-pollen allergy, were assessed.

\section{Materials and methods}

\section{Subjects}

Eighty-two unrelated patients living in the central area of Poland (46 females, 36 males, mean age 28.17 yrs, range 17-61 yrs) with grass-pollen allergy manifesting as seasonal rhinitis and/or asthma were randomly selected for the study from patients treated in the outpatient unit of the authors' dept. All subjects had a clear history of seasonal symptoms from May to August for at least three consecutive seasons. All patients had positive skin-prick tests to mixed grass pollens. Based on personal history and clinical examination during grass-pollen seasons the patients were classified into two groups. The first group included patients who had rhinorrhea, nasal obstruction and sneezing and no symptoms from the lower airways during pollen seasons (rhinitis group). Subjects were classified as having asthma and rhinitis (asthma/rhinitis group) if they had a history of coughing, wheezing and shortness of breath together with symptoms of rhinitis during at least two consecutive grass-pollen seasons. Forty-two patients with rhinitis only and 40 patients with asthma and rhinitis were studied (table 1). None of the patients had symptoms of asthma and/or rhinitis at any other times during the year. None of the patients had received immunotherapy.

Skin-prick tests with inhaled allergens followed by skin-prick tests with specific grasses were performed. For specific-grasses testing the following allergens were used: Phleum pratense, Poa pratensis, Festuca elatior, Dactylis glomerata, Lolium perenne (Allergopharma, Reinbeck, Germany). The positive control was histamine $\left(10 \mathrm{mg} \cdot \mathrm{mL}^{-1}\right)$ and the diluent was used as a negative control. A positive skin-prick test was defined as a mean weal diameter of at least $3 \mathrm{~mm}$ or larger than that of the negative control, accompanied by flare reaction.

All patients had positive skin-prick tests to mixed grass pollen and all specific grasses tested. Mean weal diameter of skin-prick test to mixed grass pollen in the rhinitis group was $11.0 \pm 3.9 \mathrm{~mm}$ and did not differ significantly from asthma/rhinitis group $(11.3 \pm 4.0 \mathrm{~mm})$. Similarly, no significant differences between both groups were found comparing mean weal diameter of skin-prick tests to any of the specific grasses tested. Frequencies of positive skin-prick tests to other allergens tested did not differ significantly between both groups and they were as follows: Dermatophagoides farinae $-26.2 \%$ and $30 \%$; Dermatophagoides pteronyssinus $28.6 \%$ and $32.5 \%$; Alternaria spp. $16.7 \%$ and $10 \%$; cat dander $42.8 \%$ and $37.5 \%$; dog dander $19 \%$ and $20 \%$; mixed tree pollens $52.4 \%$ and $47.5 \%$; mixed weed pollens $71.4 \%$ and $62.5 \%$ in rhinitis and asthma/rhinitis groups, respectively.

The control nonatopic group consisted of 52 unrelated subjects from the central area of Poland (ethnically similar to case group) with negative history of atopic diseases, no history of allergy in parents or siblings and with negative skin-prick tests to a panel of inhaled allergens (table 1).

\section{Bronchodilator response}

Spirometry was performed using ABCPneumo 2000RS spirometer (AbcMed, Kracow, Poland) during pollen seasons in all patients from asthma/ rhinitis group and in 30 patients from rhinitis group. At least three measurements in the standing position were performed and the best result was recorded. Then $200 \mu \mathrm{g}$ of salbutamol was administered by metered-dose inhaler followed by a second spirometry measurement after $15 \mathrm{~min}$. Changes in forced expiratory volume in one second $(\triangle \mathrm{FEV} 1)$ before and after drug inhalation were calculated according to the following formula:

$$
\frac{100 \times\left(\text { postsalbutamol } \mathrm{FEV}_{1}-\text { initial } \mathrm{FEV}_{1}\right)}{\text { initial } \mathrm{FEV}_{1}}
$$

Table 1.-Characteristics of the study groups

\begin{tabular}{lccc}
\hline & Rhinitis & Asthma/rhinitis & Nonatopic controls \\
\hline Subjects n & 42 & 40 & 52 \\
Age yrs mean \pm SD (range) & $27.7 \pm 7.2(17-50)$ & $28.6 \pm 9.4(19-61)$ & $27.9 \pm 5.6(20-48)$ \\
Female:male & $26: 16$ & $22: 18$ & $32: 20$ \\
Active smokers \% & 11.9 & 12.5 & 11.5 \\
Mean $\Delta$ FEV $\% \pm$ SD & $3.5 \pm 3.2$ & $10.9 \pm 5.2$ & $36.7(4.6-195.1)$ \\
Median total IgE IU $\cdot \mathrm{mL}^{-1}$ (range) & $171.3(16.8-1000)$ & $199.2(49.3-1000)$ & $11.3 \pm 4.0$ \\
Mean wheal diameter $\mathrm{mm} \pm \mathrm{SD}$ & $11.0 \pm 3.9$ & & \\
\hline
\end{tabular}

FEV1: forced expiratory volume in one second; IgE: immunoglobulin-E. 


\section{Total serum immunoglobulin E measurements}

In all subjects total serum IgE levels during pollen season were determined using the enzymelinked immunosorbant assay (ELISA) method (Sanofi Pasteur, Paris, France) according to the manufacturer's protocol. Considering a non-normal distribution of total IgE levels in the groups, a total IgE level was defined as a qualitative trait, and a cut-off point was set beyond the highest total IgE level in the nonatopic group $\left(195.1 \mathrm{IU} \cdot \mathrm{mL}^{-1}\right)$. So patients with total IgE levels $>200 \mathrm{IU} \cdot \mathrm{mL}^{-1}$ were considered as high $\mathrm{IgE}$ responders.

\section{Human leucocyte antigen-DR B typing}

Genomic deoxyribonucleic acid (DNA) was extracted from peripheral blood using "Easy Blood DNA Prep" (A\&A, Gdansk, Poland) according to the original protocol. Molecular HLA-DR typing was performed using polymerase chain reaction (PCR) with specific sequence primers technology (Dynal, Oslo, Norway) as previously described [19]. One HLA-DRB typing included 24 PCR reactions. Each PCR reaction $(10 \mu \mathrm{L})$ consisted of PCR buffer (DNA, Gdansk,Poland), $200 \mu \mathrm{M}$ of deoxyribonucleoside trisphosphate (DNA), 5\% glicerol (Sigma, Poznan, Poland), cresol red $\left(100 \mu \mathrm{g} \cdot \mathrm{mL}^{-1}\right)$ (Sigma), $0.5 \mathrm{U}$ Taq Polymerase (DNA), genomic DNA $(200 \mathrm{ng})$ and specific primers $(1 \mu \mathrm{M})$. PCR amplifications were carried out in GeneAmp 2400 (PerkinElmer, Warsaw, Poland) using the following parameters: 2 min $-94^{\circ} \mathrm{C}, 10$ cycles of $15 \mathrm{~s}$ at $94^{\circ} \mathrm{C}$ and $45 \mathrm{~s}$ at $66^{\circ} \mathrm{C}, 20$ cycles of $10 \mathrm{~s}$ at $94^{\circ} \mathrm{C}, 30 \mathrm{~s}$ at $61^{\circ} \mathrm{C}$ and $30 \mathrm{~s}$ at $72^{\circ} \mathrm{C}$. PCR products were analysed in $2 \%$ agarose gel stained with ethidium bromide and visualised under ultra violet illumination.

\section{Statistical analysis}

The frequencies of HLA-DRB alleles in patients and controls were compared with two-sided Fisher's exact test. A p-value $<0.05$ was considered significant. To correct for incidental significance, the p-value was multiplied by the number of alleles compared (pcor). Odds ratio (OR) was calculated as the cross product in a $2 \times 2$ table within $95 \%$ confidence intervals (CI). For the comparison of log total IgE levels, skin-prick tests and spirometry results Mann-Whitney and the student's t-tests were used, as appropriate.

\section{Results}

Human leucocyte antigen-DRB alleles and different phenotypes of grass-pollen allergy

The distribution of HLA-DRB alleles in patients with symptoms of asthma/rhinitis, rhinitis only and in the control nonatopic group is shown in table 2 .

Comparison of patients with asthma/rhinitis and patients with rhinitis only revealed higher frequencies
Table 2. - Human leucocyte antigen (HLA)-DR B alleles frequency in patients with grass-pollen allergy manifested as asthma/rhinitis, rhinitis only and in control nonatopic subjects

\begin{tabular}{lccc}
\hline & $\begin{array}{c}\text { Rhinitis } \\
\text { only }\end{array}$ & $\begin{array}{c}\text { Asthma/ } \\
\text { rhinitis }\end{array}$ & $\begin{array}{c}\text { Control } \\
\text { nonatopic }\end{array}$ \\
\hline Chromosomes n & 84 & 80 & 104 \\
DR B alleles & $13(15.5)$ & $9(11.2)$ & $7(6.7)$ \\
B1*01 & $4(4.76)$ & $15(17.5)^{\#}$ & $13(12.5)$ \\
B1*15 & $2(2.38)$ & $9(11.25)^{*}$ & $3(2.88)$ \\
B1*16 & $9(10.7)$ & $5(6.2)$ & $10(9.6)$ \\
B1*03 & $11(13.1)$ & $4(5.0)$ & $12(11.5)$ \\
B1*04 & $18(21.4)$ & $14(17.5)$ & $15(14.4)$ \\
B1*07 & $2(2.4)$ & $2(2.5)$ & $2(1.9)$ \\
B1*08 & $1(1.2)$ & 0 & $1(0.9)$ \\
B1*09 & $1(1.2)$ & 0 & $5(4.8)$ \\
B1*10 & $11(13.1)$ & $8(10.0)$ & $17(16.3)$ \\
B1*11 & $3(3.6)$ & $3(3.7)$ & $9(8.6)$ \\
B1*12 & $8(9.5)$ & $11(13.7)$ & $7(6.7)$ \\
B1*13 & $1(1.2)$ & 0 & $3(2.9)$ \\
B1*14 & & & \\
DR B & $32(38.1)$ & $27(33.7)$ & $46(44.2)$ \\
genes/haplotypes & $30(35.7)$ & $18(22.5)$ & $28(26.9)$ \\
B 3* & $6(7.1)$ & $24(30.0)^{+}$ & $16(15.4)$ \\
B 4* & &
\end{tabular}

Data are presented as alleles $\mathrm{n}(\%)$. ${ }^{\#}: \mathrm{p}=0.006$, p-value corrected for incidental significance $(\mathrm{pcor})=\mathrm{NS}$ versus rhinitis group; $\because \mathrm{p}=0.03$, $\mathrm{pcor}=\mathrm{NS}$ versus rhinitis group and versus nonatopic controls; ${ }^{+}: \mathrm{p}=0.0002$, $\mathrm{pcor}=0.003$ versus rhinitis group and $\mathrm{p}=0.02$, $\mathrm{pcor}=\mathrm{NS}$ versus nonatopic controls.

of DRB1*15 $(\mathrm{p}=0.006)$ and $\mathrm{DRB} 1 * 16(\mathrm{p}=0.03)$ alleles in patients having asthma, but the differences did not remain significant after correction. However, when the frequency of both alleles (DRB $1 * 15$ and $\mathrm{B} 1 * 16$; assigned as $\mathrm{DRB} 1 * 02$ ) was analysed, the significantly higher frequency of DRB $1 * 02$ alleles $(\mathrm{OR}=5.57,95 \% \mathrm{CI}=2.14-14.53$, $\mathrm{p}=0.0002$, pcor $=0.003)$ was observed in patients with asthma/rhinitis. A similarly higher frequency in the asthma/rhinitis group compared to rhinitis only patients was observed for the independently typed DR B5* gene and $\mathrm{DRB} 1 * 02 / \mathrm{B} 5 *$ haplotype $(\mathrm{OR}=5.57,95 \% \mathrm{CI}=2.14$ $14.53, \mathrm{p}=0.0002$, pcor=0.003). When subgroups of patients were compared with the nonatopic group, higher frequencies of alleles DRB $1 * 16 \quad(\mathrm{p}=0.03)$, $\mathrm{DRB} 1 * 02 \quad(\mathrm{p}=0.02)$ and DRB5* $(\mathrm{p}=0.02)$ were observed in asthma/rhinitis patients, but the differences became insignificant upon correction. There were no significant differences in HLA-DR allele distribution between patients with rhinitis only and the nonatopic group as well as between the entire group of patients with grass-pollen allergy and the nonatopic group.

\section{Human leucocyte antigen alleles and specific immunoglobulin-E response}

There was no significant association between the level of grass-pollen specific IgE response measured by skin-prick tests (to mixed and specific grass-pollen 
allergens) and HLA-DRB allelic distribution in the patients.

Human leucocyte antigen alleles and bronchodilator
response

Mean $\triangle F E V 1$ after salbutamol inhalation in the asthma/rhinitis group was $10.9 \pm 5.2 \%$ and was significantly higher than $\triangle \mathrm{FEV} 1$ in rhinitis patients $(3.5 \pm 3.23 \%, \mathrm{p}<0.0001)$. However, there was no significant association between the airway reversibility and HLA-DRB allele distribution in the patients studied $(n=70)$.

Human leucocyte antigen alleles and total serum immunoglobulin-E

The distribution of total serum IgE levels and their logarithmic transformed values (tIgE) in all groups studied did not show a normal distribution characteristic for quantitative traits (the data was skewed to lower IgE values). There was no significant difference in the median total IgE levels between patients with rhinitis only and patients with asthma/rhinitis symptoms. Significantly higher tIgE levels $(\mathrm{p}=0.004)$ were found in patients with the DRB*01 allele (median $394.9 \mathrm{IU} \cdot \mathrm{mL}^{-1}$ ) in comparison to patients without this allele (median $163.1 \mathrm{IU} \cdot \mathrm{mL}^{-1}$ ) when total $\mathrm{IgE}$ levels in respect to the distribution of HLA-DR alleles in the whole group of patients with grass-pollen allergy was analysed. However, when the nonatopic control group was analysed, there was no significant difference between tIgE levels in subjects with or without the DRB*01 allele (fig. 1).

As the total IgE levels in the groups were not normal distributed, total IgE levels were also analysed as a qualitative trait. The group of patients with total IgE levels $>200 \mathrm{IU} \cdot \mathrm{mL}^{-1}$ (high $\mathrm{IgE}$ responders) comprised 39 patients (18 females, 21 males, mean age $28.2 \mathrm{yrs}$, range $17-61 \mathrm{yrs})$. Twenty $(51.3 \%)$ of them had symptoms of asthma and rhinitis and 19 $(48.7 \%)$ rhinitis only. Forty-three patients (26 females, 17 males, mean age 28.2 yrs, range $19-54$ yrs) were included in the group with total IgE levels $<200 \mathrm{IU} \cdot \mathrm{mL}^{-1}$ and defined as low $\mathrm{IgE}$ responders. Twenty patients $(46.5 \%)$ had asthma/rhinitis symptoms and $23(53.5 \%)$ symptoms of rhinitis only. The frequencies of HLA-DRB alleles in both groups are shown in table 3. A higher frequency of HLADRB1*01 alleles was found in the group of high $\mathrm{IgE}$ responders $\left(\mathrm{tgE}>200 \mathrm{IU} \cdot \mathrm{mL}^{-1}\right)$ in comparison to low $\mathrm{IgE}$ responders $(\mathrm{OR}=6.15 .95 \% \mathrm{CI}=1.98-19.1$, $\mathrm{p}=0.0009, \mathrm{p}$ cor $=0.01)$. A significantly higher frequency of DRB $1 * 01$ alleles was also found in patients with IgE levels $>200 \mathrm{IU} \cdot \mathrm{mL}^{-1}$ in comparison to the control nonatopic group $(\mathrm{OR}=4.16,95 \% \mathrm{CI}=1.164-10.54$, $\mathrm{p}=0.002$, $\mathrm{pcor}=0.026$ ). A lower frequency of $\mathrm{DRB} 1 * 07$ was observed in patients with high IgE levels compared to the low $\operatorname{IgE}$ responders group $(\mathrm{OR}=0.36$, $\mathrm{p}=0.02)$, although this was not significant after correction. There was no significant association of HLA alleles with high total IgE levels when the cut-off a)

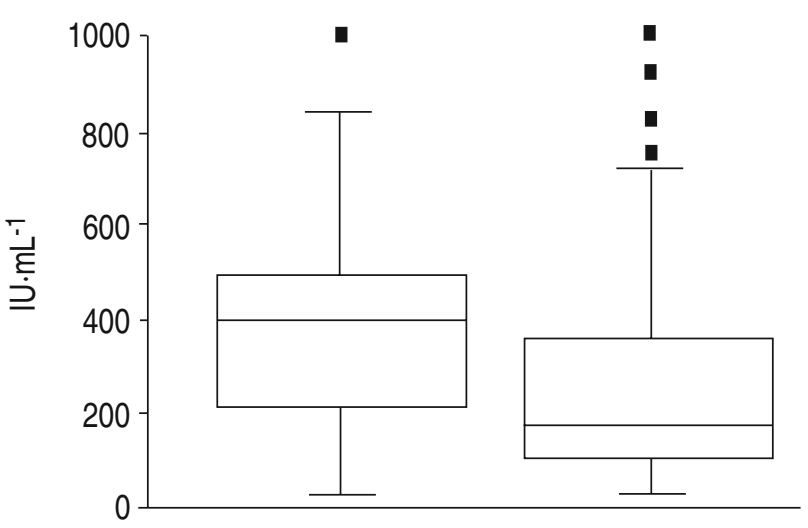

b)

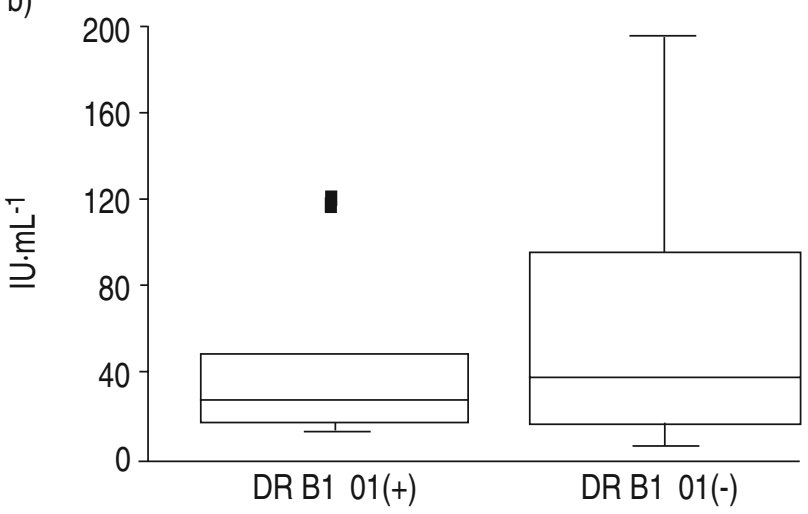

Fig. 1.-Comparison of total immunoglobulin (Ig)E levels in a) atopic patients and b) control nonatopic subjects with (DR $\left.\mathrm{B} 1 *^{*} 1(+)\right)$ and without (DR B1*01(-)) the human leucocyte antigen (HLA)-DR B1*01 allele. Data are presented as a box-andwhisker plot with the central box covering the middle $50 \%$ of the data, the vertical line through the box represents the median and the whiskers the range. The outliers are shown as single points beyond the whiskers. a) DR $\mathrm{B} 1 * 01(+) \mathrm{n}=22$, DR B1*01(-) $\mathrm{n}=60$, $\mathrm{p}<0.004$ and b) DR B1*01(+) n=7, DR B1*01(-) n=45, p=NS.

level was set at $100 \mathrm{IU} \cdot \mathrm{mL}^{-1}$ (mean total $\mathrm{IgE}+1 \mathrm{SD}$ in nonatopic group).

\section{Discussion}

Symptoms of atopic allergy may manifest in different patients with various collections of organs affected. In this study, patients sensitised to grass pollens with symptoms of seasonal asthma and rhinitis had a significantly higher frequency of the HLA-DRB1*02/DRB5* haplotype in comparison to patients with rhinitis only, but not to nonatopic group. A highly significant increase in this HLA haplotype in patients with asthma $(47.5 \%)$ in comparison to patients with rhinitis only $(14 \%)$ and lack of such an association in comparison to the nonatopic group could be explained by a high frequency of the DRB1*02/DRB5* haplotype $(29 \%)$ in the control group. A similar frequency (33\%) of this haplotype was observed in the general population of central Poland [20]. It is well known that atopic diseases, 
Table 3. - Comparison of human leucocyte antigen (HLA)-DR B1 allele frequencies between atopic patients with total immunoglobulin (Ig) E levels $>200 \mathrm{IU} \cdot \mathrm{mL}^{-1}$ and patients with total $\mathrm{lgE}$ levels $<200 \mathrm{IU} \cdot \mathrm{mL}^{-1}$

\begin{tabular}{|c|c|c|c|c|c|}
\hline Allele DR B1* & Total $\mathrm{IgE}>200 \mathrm{IU} \cdot \mathrm{mL}^{-1}$ & Total $\mathrm{IgE}<200 \mathrm{IU} \cdot \mathrm{mL}^{-1}$ & OR & p-value & pcor \\
\hline Chromosomes $\mathrm{n}$ & 78 & 86 & & & \\
\hline 01 & $18(23.08)$ & $4(4.65)$ & 6.15 & 0.0009 & 0.01 \\
\hline 15 & $5(6.41)$ & $14(16.28)$ & & & \\
\hline 16 & $4(5.13)$ & $7(8.14)$ & & & \\
\hline 03 & $8(10.25)$ & $6(6.98)$ & & & \\
\hline 04 & $8(10.26)$ & $7(8.14)$ & & & \\
\hline 07 & $9(11.54)$ & $23(26.74)$ & 0.36 & 0.02 & NS \\
\hline 08 & $3(3.84)$ & $1(1.16)$ & & & \\
\hline 09 & $1(1.28)$ & 0 & & & \\
\hline 10 & $1(1.28)$ & 0 & & & \\
\hline 11 & $8(10.25)$ & $11(12.79)$ & & & \\
\hline 12 & $3(3.84)$ & $3(3.49)$ & & & \\
\hline 13 & $9(11.54)$ & $10(11.63)$ & & & \\
\hline 14 & $1(1.28)$ & 0 & & & \\
\hline
\end{tabular}

Data are presented as alleles n (\%) unless otherwise stated. OR: odds ratio; pcor: p-value corrected for incidental significance.

including asthma, are determined by numbers of genes, thus to find a relevant gene association, a sufficiently large population or appropriate selection of control groups are required. The data in this study suggest that presence of asthma in patients with grass-pollen allergy might be partly related to the presence of the HLA-DRB1*02/DRB5* haplotype or other genes in strong linkage disequilibrium. Similar frequencies of the DRB1*02/DRB5* haplotype in nonatopic and entire groups of patients with grasspollen allergy observed in this study suggests that the genes of interest are not associated with atopy or grass-pollen allergy, but that they can determine more intensive inflammatory responses to specific stimuli, leading to a more generalised immune response. It has been reported that a potent pro-inflammatory cytokine TNF- $\alpha$ gene polymorphism, which is in linkage disequilibrium with the HLA loci, may affect cytokine generation and also the severity of the disease [21]. Interestingly, an association of extended TNF- $\alpha$ haplotype (LT $\alpha$ NcoI*1/TNF-308*2/HLA-DRB1*02) and asthma has also been reported [18], suggesting that it is the combination of different polymorphic loci localised to chromosome 6 (particular extended haplotype) that influences asthma phenotype. HLADR locus association probably represents a linkage disequilibrium phenomenon only.

When the patients with asthma/rhinitis and patients with rhinitis only were compared considering age, sex, active smoking status, total IgE levels and specific $\mathrm{IgE}$ response to grasses and other inhaled allergens analysed by skin-prick tests, no significant differences were found between both groups. The only anticipated difference found, apart from differentially manifested symptoms, was the bronchial airway reversibility after salbutamol inhalation. A significantly higher $(p<0,0001)$ response to the bronchodilator was observed in patients having asthma compared to patients with rhinitis only. Asthma is usually defined by three characteristic features namely, intermittent reversible airway obstruction, airway hyperresponsiveness and airway inflammation. Although each of these components is recognised as an important part of the asthmatic phenotype, it has been shown recently that bronchial airway responsiveness as well as airway reversibility and the inflammatory process in airways might be differentially determined [22]. In this study asthmatic patients were selected based on a consistent history of asthma symptoms during several consecutive pollen seasons. Recent data have shown that spirometric criteria for asthma diagnosis, including response to a bronchodilator, should be re-evaluated as a parameter for clinical trials inclusion [23]. In this study in contrast to the study of Blumenthal et al. [17] the airway reversibility was not a selection criterion. When the group of patients having asthma was divided according to the degree of airway reversibility on high responders $(\triangle \mathrm{FEV} 1>12 \%)$ and low responders $(\triangle \mathrm{FEV} 1<12 \%)$ there were no significant differences in HLA-DR allele distribution between both groups (data not shown). In the study of BlumENTHAL et al. [17], where $15 \%$ reversal of FEV1 was the of selection criteria, no significant association of HLA-DR2 alone with the asthmatic phenotype was observed. These data suggest that increased frequency of DRB1*02/DRB5* haplotype is not directly associated with airway reversibility, but rather with some other features of the asthma phenotype.

The second most important finding in this study was the strong association of total serum IgE levels with HLA-DRB $1 * 01$ alleles. These data are consistent with the study of ULBRECHT et al. [24] who found the association of high total IgE levels with HLADRB $1 * 01$ in the German population. In their study the association was not significant until specific $\operatorname{IgE}$ positive cases were selected. The stronger associations observed in this study can be explained by the fact that all of the patients with grass-pollen allergy had specific IgE to grass pollens determined by skinprick tests. Further support for the role of the HLA region comes from a genome-wide search showing associations of high total IgE levels with markers on chromosome 6 [5]. In studies where the atopy status was defined based on the disease phenotype and specific $\operatorname{IgE}$ responsiveness to perennial allergens 
(HDM) and not on total IgE levels, no associations of HLA loci with atopy were observed [25]. Accordingly, the data from this study suggest that high total IgE titres may be related to specific HLA-DR locus independently of allergic phenotypes and could be associated with upregulation of $\operatorname{IgE}$ regulatory mechanisms. In the meantime, a significant association of total IgE levels with DRB1*0701 has been reported in the British population and with DRB $1 * 01$ in Australian families, confirming a significance of association of HLA-DR locus with total IgE [26, 27].

HLA alleles probably act in association with other loci involved in total IgE regulation. For example it has been shown that very strong genetic determinants of high total IgE levels lie on chromosome 11q [9] and $5 q$ [28], which further complicates the picture of genetic regulation of the total IgE response.

To conclude, this study suggests a strong association of the human leucocyte antigen-DRB $1 * 02 / \mathrm{B} 5 *$ haplotype with the asthmatic phenotype in grasspollen sensitive patients. Furthermore, a significant association of DRB $1 * 01$ allele, irrespective of grasspollen allergy phenotype, with high total immunoglobulin E levels was demonstrated, suggesting that the role of human leucocyte antigen locus in the pathophysiology of atopic allergy is not restricted to specific allergic response.

\section{References}

1. D'Amato G, Spieksma FT, Liccardi G, et al. Pollenrelated allergy in Europe. Allergy 1998; 53: 567-578.

2. Danielsson J, Jessen M. The natural course of allergic rhinitis during 12 years of follow-up. Allergy 1997; 52: 331-334.

3. Settipane RJ, Hagy GW, Settipane GA. Long-term risk factors for developing asthma and allergic rhinitis: a 23-year follow-up study of college students. Allergy Proc 1994; 15: 21-25.

4. Mao XQ, Shirakawa T, Yoshikawa T, et al. Association between genetic variants of mast-cell chymase and eczema. Lancet 1996; 348: 581-583.

5. Daniels SE, Bhattacharrya S, James A, et al. A genome-wide search for quantitative trait loci underlying asthma. Nature 1996; 383: 247-250.

6. Wjst M, Fischer G, Immervoll T, et al. A genome-wide search for linkage to asthma. German Asthma Genetics Group. Genomics 1999; 58: 1-8.

7. Postma DS, Bleecker ER, Amelung PJ, et al. Genetic susceptibility to asthma - bronchial hyperresponsiveness coinherited with a major gene for atopy. $N$ Engl J Med 1995; 333: 894-900.

8. Burrows B, Martinez FD, Halonen M, Barbee RA, Cline MG. Association of asthma with serum IgE levels and skin-test reactivity to allergens. $N$ Engl J Med 1989; 320: 271-277.

9. Cookson WO, Sharp PA, Faux JA, Hopkin JM. Linkage between immunoglobulin $\mathrm{E}$ responses underlying asthma and rhinitis and chromosome 11q. Lancet 1989; 1: 1292-1295.

10. Rosenwasser LJ, Klemm DJ, Dresback JK, et al. Promoter polymorphisms in the chromosome 5 gene cluster in asthma and atopy. Clin Exp Allergy 1995; 25: Suppl. 2, 74-78.
11. Bazaral M, Orgel HA, Hamburger RN. IgE levels in normal infants and mothers and an inheritance hypothesis. J Immunol 1971; 107: 794-801.

12. Hanson B, McGue M, Roitman-Johnson B, Segal NL, Bouchard TJJ, Blumenthal MN. Atopic disease and immunoglobulin $\mathrm{E}$ in twins reared apart and together. Am J Hum Genet 1991; 48: 873-879.

13. Omenaas E, Bakke P, Elsayed S, Hanoa R, Gulsvik A. Total and specific serum IgE levels in adults: relationship to sex, age and environmental factors. Clin Exp Allergy 1994; 24: 530-539.

14. Marsh DG, Hsu SH, Roebber M, et al. HLA-Dw2: a genetic marker for human immune response to short ragweed pollen allergen Ra5. I. Response resulting primarily from natural antigenic exposure. J Exp Med 1982; 155: 1439-1451.

15. $\mathrm{O}^{\prime}$ Hehir RE, Mach B, Berte C, et al. Direct evidence for a functional role of HLA-DRB1 and -DRB3 gene products in the recognition of Dermatophagoides spp. (house dust mite) by helper $\mathrm{T}$ lymphocytes. Int Immunol 1990; 2: 885-892.

16. Kowalski ML, Woszczek G, Bienkiewicz B, Mis M. Association of pyrazolone drug hypersensitivity with HLA-DQ and DR antigens. Clin Exp Allergy 1998; 28: $1153-1158$.

17. Blumenthal M, Marcus-Bagley D, Awdeh Z, Johnson B, Yunis EJ, Alper CA. HLA-DR2, [HLA-B7, SC31, DR2], and [HLA-B8, SC01, DR3] haplotypes distinguish subjects with asthma from those with rhinitis only in ragweed pollen allergy. J Immunol 1992; 148: 411-416.

18. Moffatt MF, James A, Ryan G, Musk AW, Cookson WO. Extended tumour necrosis factor/HLA-DR haplotypes and asthma in an Australian population sample. Thorax 1999; 54: 757-761.

19. Woszczek G, Borowiec M, Mis M, Gorska M, Kowalski ML. Comparison of serological and molecular (PCR-SSP) techniques of HLA-DR typing in clinical laboratory routine. Ann Transplant 1997; 2: $39-42$.

20. Krokowski M, Bodalski J, Bratek A, Boitard C, Caillat-Zucman S. HLA class II allele and haplotype distribution in a population from central Poland. Eur J Immunogenet 1998; 25: 5-9.

21. Brinkman BM, Huizinga TW, Kurban SS, et al. Tumour necrosis factor alpha gene polymorphisms in rheumatoid arthritis: association with susceptibility to, or severity of, disease? $\mathrm{Br} J$ Rheumatol 1997; 36: 516-521.

22. Crimi E, Spanevello A, Neri M, Ind PW, Rossi GA, Brusasco V. Dissociation between airway inflammation and airway hyperresponsiveness in allergic asthma. Am J Respir Crit Care Med 1998; 157: 4-9.

23. Cockcroft DW, Jokic R, Marciniuk DD, Fitzpatrick MF. The current dilemma with spirometric inclusion criteria for asthma drug trials. Ann Allergy Asthma Immunol 1997; 79: 226-228.

24. Ulbrecht M, Eisenhut T, Bonisch J, et al. High serum IgE concentrations: association with HLA-DR and markers on chromosome $5 \mathrm{q} 31$ and chromosome 11q13. J Allergy Clin Immunol 1997; 99: 828-836.

25. Holloway JW, Doull I, Begishvili B, Beasley R, Holgate ST, Howell WM. Lack of evidence of a significant association between HLA-DR, DQ and DP genotypes and atopy in families with HDM allergy. Clin Exp Allergy 1996; 26: 1142-1149. 
26. Mansur AH, Williams GA, Bishop DT, et al. Evidence for a role of HLA DRB1 alleles in the control of $\operatorname{IgE}$ levels, strengthened by interacting TCR A/D marker alleles. Clin Exp Allergy 2000; 30: 1371-1378.

27. Moffatt MF, Schou C, Faux JA, et al. Association between quantitative traits underlying asthma and the
HLA-DRB1 locus in a family-based population sample. Eur J Hum Genet 2001; 9: 341-346.

28. Marsh DG, Neely JD, Breazeale DR, et al. Linkage analysis of IL4 and other chromosome 5q31.1 markers and total serum immunoglobulin E concentrations. Science 1994; 264: 1152-1156. 